Mediterráneo. Acta Bot. Malacitana 17: 245249.

FLORES-MOYA, A. y F. CONDE -1998- Nuevas citas de macroalgas marinas para las Islas Chafarinas. Acta Bot. Malacitana 23: 197-199. GONZÁLEZ, J.A. y F. CONDE - 1994- Catálogo del macrofitobentos del Mediterráneo de Marruecos. Acta Bot. Malacitana 9: 5-28.

NAVARRO, M.J. y T. GALLARDO -1989Aportación al conocimiento de la flora bentónica de las costas africanas occidentales. Bot. Complutensis 15: 203-214.

PERRET-BOUDERESQUE, M. y H. SERIDI -1989Inventaire des algues marines benthiques d'Algerie. GIS Posidonie. $116 \mathrm{pp}$.
TREVISAN, V.B.A. - 1845- Nomenclator algarum. Padua $80 \mathrm{pp}$.

Aceptado para su publicación en Septiembre de 1999

Dirección de la autora. Departamento de Biología Vegetal. Facultad de Ciencias. Universidad de Málaga. Campus de Teatinos s/n. E-29071 Málaga. España.

\title{
76. ALGUNAS PLANTAS NUEVAS O INTERESANTES PARA LA FLORA DE BADAJOZ
}

\author{
José Luis RODRÍGUEZ MARZAL
}

Some new or interesting plants for the flora of Badajoz

Palabras clave. Corología, Badajoz, Extremadura, España.

Key words. Corology, Badajoz, Extremadura, Spain.

Lunaria annua L., Sp. Pl.: 653 (1753) subsp. annua

BADAJOZ: Villarta de los Montes, 30SUJ4540, $600 \mathrm{~m}$, herbazales húmedos en los claros de un castañar, 13-V-1999, J. L. Rodríguez Marzal, MA 627158.

Crucífera alóctona -originaria del SE de Europa- de la que no conocemos referencias anteriores para la provincia de Badajoz (García Adá, 1993: 165; Ortega, 1995: 323). Hemos encontrado una pequeña población naturalizada en el extremo nororiental de la provincia, creciendo en un claro herboso muy húmedo de un castañar maduro situado en las proximidades de Villarta de los Montes.

Hypericum androsaemum L., Sp. Pl.: 784 (1753)

BADAJOZ: Villarta de los Montes, 30SUJ4540, $600 \mathrm{~m}$, bordes de arroyo bajo un bosque denso de castaños, 13-V-1999, J. L. 
Rodríguez Marzal, MA 627159.

Taxón atlántico y submediterráneo típicamente esciófilo, abundante en los bosques caducifolios mesofíticos del norte de la Península Ibérica. Dentro de Extremadura, su presencia es conocida en la provincia de Cáceres desde que Willkomm \& Lange (1880) lo citaran en su Prodromus. Posteriormente, otros autores lo han encontrado en diversas comarcas montañosas de la provincia: Las Villuercas (Ladero, 1970), Baños de Montemayor (Rivas Goday \& Sánchez Egea, 1975) y la Sierra de Gata (Valdés Franzi, 1984, 1985). En la provincia de Badajoz sólo se conoce la referencia de Rivas Goday (1964: 551), quien incluyó este taxón en uno de sus inventarios fitosociológicos «de las cabezas de valles en Monesterio y Calera de León», correspondiente a un bosque ripario de fresnos y alisos situado a $680 \mathrm{~m}$ de altitud. Al parecer no se han conservado pliegos de herbario de estas localidades del extremo meridional de la provincia, donde la planta no ha vuelto a ser encontrada. Más recientemente, Ramos Núñez (1993: 161-162) sitúa un interrogante junto a la provincia de Badajoz al repasar la distribución ibérica de este taxón. El hallazgo de una población en Villarta de los Montes confirma la presencia de esta bella planta en la provincia de Badajoz. Las citas más próximas que conocemos se localizan en la vertiente ciudarrealeña de la comarca de Los Montes, donde de esta especie resulta muy rara, apareciendo en contados lugares formando parte de las comunidades higrófilas de las hoces, manantiales y otros enclaves con humedad permanente (Martín Blanco \& Carrasco, 1998).

Los ejemplares de $H$. androsaemum se encuentran en el interior de un bosque denso y maduro de castaños, creciendo a lo largo de un arroyo en uno de los rincones más húmedos y sombríos, en compañía de otras plantas muy exigentes en humedad, como Frangula alnus, Osmunda regalis, Sibthorpia europaea,
Dryopteris affinis, Blechnum spicant y Athyrium filix-foemina. Junto a estas plantas de óptimo atlántico, en este interesante castañar se encuentran otros muchos taxones nemorales y acidófilos de tendencia montana, entre los que pueden destacarse, por estar escasamente citados en la provincia, Luzula forsteri y Dactylorhiza sulphurea.

Este hallazgo viene a sumarse a otros que se vienen produciendo en los últimos tiempos y que están contribuyendo a mejorar el conocimiento de la distribución de este taxón en el sur de la Península Ibérica y norte de África, territorios donde resulta muy escaso y localizado. Así, Molina Moreno et al. (1994) lo encuentran en el tramo jiennense de Sierra Morena, en una garganta fluvial situada dentro de los límites de la finca estatal «SelladoresContadero» (Andújar). Poco después, Pérez Latorre et al. (1996) lo localizan en el interior de un quejigar de Quercus canariensis del valle del río Genal, en Casares (Málaga). Por último, Galán de Mera et al. (1997) encuentran esta especie por vez primera en Marruecos, creciendo en un bosque rifeño de Prunus lusitanica. En estos lugares, $H$. androsaemum delata con su presencia enclaves microclimáticos muy húmedos, en los que las condiciones de mediterraneidad del clima dominante se encuentran muy atenuadas. Las manifestaciones meridionales de este taxón representan relictos de un clima pretérito más húmedo que el actual (cf. Galán de Mera et al., l.c.).

Erica lusitanica Rudolphi in J. Bot. (Schrader) 1799(2): 286 (1800)

BADAJOZ: Villarta de los Montes, Arroyo del Robledillo, 30SUJ4242, $540 \mathrm{~m}$, cuarcitas, 14-V-1999, J. L. Rodríguez Marzal, MA 627121. Helechosa, Garganta de los Acebos, 30SUJ4551, $520 \mathrm{~m}$, suelos húmedos próximos al arroyo, 14-V-1999, J. L. Rodríguez Marzal, MA 627120. 
Primeras localidades pacenses de este taxón de distribución fundamentalmente iberoatlántica, del que no conocemos citas provinciales previas (Bayer, 1993: 504; Viera \& Devesa, 1995: 336). Lo hemos encontrado creciendo sobre suelos permanentemente húmedos situados junto a cursos de agua de cierto caudal, en compañía de especies tales como Molinia caerulea, Frangula alnus, Osmunda regalis, Blechnum spicant, Salix atrocinerea, Carex pendula, Erica arborea, E. scoparia y Pteridium aquilinum. Las dos poblaciones se localizan en valles especialmente húmedos y resguardados a causa del encajamiento de los arroyos entre altas paredes de cuarcita. Este brezo de buen porte y vistosa floración resulta bastante frecuente en los lugares señalados, por lo que su presencia nos parece muy probable en otrds gargantas angostas y sombrías de la interesante comarca de Los Montes.

\section{BIBLIOGRAFÍA}

BAYER, E. -1993- Erica L. In: S. Castroviejo et al. (eds.), Flora iberica, 4: 485-506. C.S.I.C. Madrid.

GALÁN DE MERA, A., J. A. VICENTE ORELLANA y U. DEIL -1997- Hypericum androsaemum L. (Guttiferae), nueva especie para la flora de Marruecos. Anales Jard. Bot. Madrid 55(2): 466.

GARCÍA ADÁ, R. -1993- Lunaria L. In: S. Castroviejo et al. (eds.), Flora iberica 4: 165167. C.S.I.C. Madrid.

LADERO, M. -1970- Contribución al estudio de la flora y vegetación de las comarcas de La Jara, Serranía de Ibor y Guadalupe-Villuercas, en la Oretana Central. Tesis Doctoral. Madrid.

MARTÍN BLANCO, C. J. y M. A. CARRASCO 1998- Flora vascular del sector meridional de Montes Norte (Ciudad Real). Instituto de Estudios Manchegos. C.S.I.C.

MOLINA MORENO, J. R., J. M. MANCEBO y F. GÓMEZ MANZANEQUE -1994- Fragmenta Chorologica Occidentalia, 5129-5156. Anales
Jard. Bot. Madrid 52 (1): 93-94.

ORTEGA, A. -1995- Brassicaceae. In: J. A. Devesa (ed.), Vegetación y flora de Extremadura: 312333. Universitas editorial. Badajoz.

PÉREZ LATORRE, A. V., B. CABEZUDO y J. M. NIETO CALDERA -1996- Sobre la presencia de Hypericum androsaemum L. en Andalucía. Lazaroa 17: 157-159.

RAMOS NÚÑEZ, A. F. -1993- Hypericum L. In: S. Castroviejo et al. (eds.), Flora iberica 3: 157185. C.S.I.C. Madrid.

RIVAS GODAY, S. -1964- Vegetación y flórula de la cuenca extremeña del Guadiana. Publ. Excma. Diputación Provincial de Badajoz. Madrid.

RIVAS GODAY, S. y J. SÁNCHEZ EGEA -1975Fisiografía y paisaje vegetal de Baños de Montemayor (Cáceres). Anales Real Acad. Farm. (Madrid) 41: 541-590.

VALDÉS FRANZI, A. -1984- Flora y vegetación vascular de la vertiente sur de la Sierra de Gata (Cáceres). Tesis Doctoral. Universidad de Salamanca.

VALDÉS FRANZI, A. -1985- Algunas plantas interesantes en la Sierra de Gata (Cáceres). IV. Lazaroa 8: 399-401.

VIERA, M. C. y J. A. DEVESA -1995- Ericaceae. In: J. A. Devesa (ed.), Vegetación y flora de Extremadura: 335-336. Universitas editorial. Badajoz.

WILLKOMM, M. \& LANGE, J. -1880-Prodromus Florae Hispanicae, vol. 3. Stuttgart.

Aceptado para su publicación en Octubre de 1999

Dirección del autor. Avda. de Portugal, 11, $2^{\circ}$ A. 21001 Huelva 